\title{
Experimental and Theoretical Evidence for Diastereomer- and Enantiomer-Specific Accumulation and Biotransformation of HBCD in Maize Roots
}

\author{
Honglin Huang, ${ }^{\dagger}$ Shuzhen Zhang, ${ }^{* \dagger, \dagger}$ Jitao Lv, $^{\dagger}$ Bei Wen, ${ }^{\dagger}$ Sen Wang, ${ }^{\dagger, \S}$ and Tong Wu ${ }^{\dagger, \|}$ \\ ${ }^{\dagger}$ State Key Laboratory of Environmental Chemistry and Ecotoxicology, Research Center for Eco-Environmental Sciences, Chinese \\ Academy of Sciences, P.O. Box 2871, Beijing 100085, China \\ ${ }^{\ddagger}$ University of Chinese Academy of Sciences, Beijing 100049, China \\ ${ }^{\S}$ Department of Environmental Sciences, College of Urban and Environmental Sciences, Northwest University, Xi'an 710027, China \\ "School of Environmental Science and Engineering, Hebei University of Science and Technology, Hebei 050018, China
}

\section{Supporting Information}

\begin{abstract}
Diastereomer- and enantiomer-specific accumulation and biotransformation of hexabromocyclododecane (HBCD) in maize (Zea mays L.) were investigated. Molecular interactions of HBCD with plant enzymes were further characterized by homology modeling combined with molecular docking. The $(-) \alpha-,(-) \beta$-, and $(+) \gamma$-HBCD enantiomers accumulated to levels in maize significantly higher than those of their corresponding enantiomers. Bioisomerization from $(+) /(-)-\beta$ - and $\gamma$-HBCDs to $(-) \alpha$-HBCD was frequently observed, and $(-) \gamma$-HBCD was most easily converted, with bioisomerization efficiency of $90.5 \pm 8.2 \%$. Mono- and dihydroxyl HBCDs, debrominated metabolites including pentabromocyclododecene (PBCDe) and tetrabromocyclododecene (TBCDe), and HBCD-GSH adducts were detected in

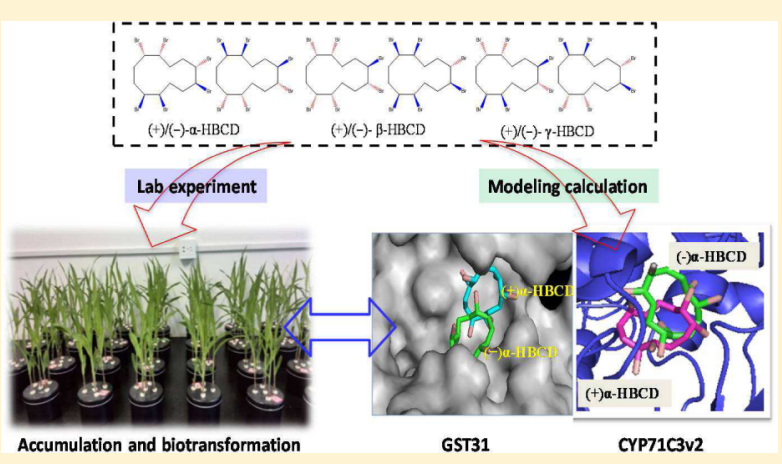
maize roots. Patterns of hydroxylated and debrominated metabolites were significantly different among HBCD diastereomers and enantiomers. Three pairs of $\mathrm{HBCD}$ enantiomers were selectively bound into the active sites and interacted with specific residues of maize enzymes CYP71C3v2 and GST31. $(+) \alpha-,(-) \beta$-, and $(-) \gamma$-HBCDs preferentially bound to CYP71C3v2, whereas $(-) \alpha-,(-) \beta$-, and $(+) \gamma$-HBCDs had strong affinities to GST31, consistent with experimental observations that $(+) \alpha-,(-) \beta$-, and $(-) \gamma$-HBCDs were more easily hydroxylated, and $(-) \alpha-,(-) \beta-$, and $(+) \gamma$-HBCDs were more easily isomerized and debrominated in maize compared to their corresponding enantiomers. This study for the first time provided both experimental and theoretical evidence for stereospecific behaviors of $\mathrm{HBCD}$ in plants.
\end{abstract}

\section{INTRODUCTION}

Hexabromocyclododecane (HBCD) is a brominated flame retardant additive mainly used in polystyrene insulation foam and textile coatings and, to a lesser extent, in high-impact polystyrene for electric and electronic devices. ${ }^{1}$ As a result of its widespread use and physical and chemical properties, HBCD has been found ubiquitously in the environment. ${ }^{1-3} \mathrm{HBCD}$ has a complex stereochemistry, and the commercial formulations consist mainly of $\alpha$-, $\beta$-, and $\gamma$-diastereomers, ${ }^{4}$ with each of them having a pair of enantiomers. Enantiomers of a chiral compound have similar physicochemical properties but can have significantly different behavior in biological systems. ${ }^{5}$ Therefore, the diastereomer- and enantiomer-specific behaviors of HBCD in organisms, such as uptake and transformation, will largely determine their fates in the environment and have drawn increasing research attention in recent years.

Soil is the main receptor for organic contaminants. HBCD has been frequently detected in soils, and high concentrations were found in soils at sites near contamination sources. For example, HBCD has been detected at concentrations of 1401300 and 111-23200 ng/kg dry weight in soils in Sweden and Belgium, respectively, near HBCD-processing factories. ${ }^{6,7}$ Heavy discharges of $\mathrm{HBCD}$ to soils have also been reported from industrial waste disposal sites and electronic waste recycling areas in the United Kingdom and China. ${ }^{8-11}$ Therefore, plant uptake and accumulation of $\mathrm{HBCD}$ are important processes determining their fates in the terrestrial environment. Nevertheless, the previous studies on bioaccumulation of HBCD have mainly focused on animal species. ${ }^{12-14}$ Plant uptake and accumulation of HBCD have only been demonstrated in one field study and several pot experiments. ${ }^{15-19}$ The concentration of HBCD was reported to be $3-28 \mathrm{ng} / \mathrm{g}$ dry weight in radish, wheat, and reed from a

Received: June 28, 2016

Revised: September 20, 2016

Accepted: October 14, 2016

Published: October 14, 2016 
natural wetland conservation area near Tianjin, China. ${ }^{18}$ Diastereomer-specific uptake and accumulation were evidenced in maize by a hydroponic experiment in our previous work, ${ }^{15}$ but so far the enantiomer selectivity of HBCD in plant uptake and accumulation remains unknown.

Biotransformation is an important process for organic contaminants with different diastereomer or enantiomer structures. To date, only a small number of studies exist on the transformation of HBCD in organisms. ${ }^{20-24}$ A diastereomeric shift toward $\alpha$-HBCD by liver microsomes of seals has been reported by Zegers et al. ${ }^{20}$ The degradation products of pentabromocyclododecene (PBCDe) and tetrabromocyclododecene (TBCDe) from HBCD have been detected in chicken eggs, whale, and whitefish (Coregonus lavaretus). ${ }^{23}$ Hydroxylated metabolites including $\mathrm{OH}-\mathrm{HBCD}$, pentabromocyclododecanols (OH-PBCDs), and tetrabromocyclododecanols $(\mathrm{OH}-$ TBCDs) have been confirmed in in vitro assays with rat and seal liver microsomes. ${ }^{20,24}$ However, the biotransformation pathway of $\mathrm{HBCD}$, particularly at the enantiomer level, is still unclear. To the best of our knowledge, there have no reported studies on biotransformation of HBCD inside plants, although the total biomass of plants is far greater than that of animals on earth, and the "green-liver" concept of plant metabolism in the transformation and degradation of organic contaminants is well-known. $^{25}$

Moreover, there is much lacking in the understanding of the molecular mechanisms for the selective accumulation and transformation of HBCD diastereomers and enantiomers in organisms. The individual enantiomers of chiral compounds can interact enantioselectively with enzymes and biological receptors in organisms. ${ }^{5,26}$ For example, Kania-Korwel et al. ${ }^{27}$ found a greater binding of (+)-PCB 136 to P450 isozymes CYP2B and CYP3A than (-)-PCB 136 in mouse and rat in vivo. The (-)-o,p,-DDT enantiomer was found to be an active estrogen mimic at the human estrogen receptor, whereas (+)-o,p,-DDT had negligible activity. ${ }^{28}$ Whether HBCD diastereomers and enantiomers interact selectively with biomacromolecules and, if so, how the selective interactions of HBCD with biomacromolecules lead to their diastereo- and enantio-specific bioaccumulation and biotransformation in organisms are not known. Homology modeling has been successfully applied to construct three-dimensional (3D) models of enzymes in organisms, which have been combined with molecular docking to characterize the interactions of stereoisomers of PCBs and pesticides with isozymes. ${ }^{29-33}$ Using homology modeling combined with molecular docking, the function of enzymes can be predicted by their 3-D structures, and the active sites of enzymes involved in stereoisomer recognition as well as the binding modes and binding affinities of stereoisomers to enzymes can be characterized. This information is helpful in elucidating the molecular mechanisms of accumulation and transformation in organisms of contaminants having various stereoisomers, such as $\mathrm{HBCD}$.

Therefore, diastereomer- and enantiomer-specific accumulation and biotransformation of HBCDs in maize were studied in the present study by exposing plants to $(+) /(-)-\alpha-, \beta$-, and $\gamma$-HBCD enantiomers individually in a hydroponic experiment. Attempts were made for the first time to clarify the molecular interactions between $\mathrm{HBCD}$ and plant cytochrome P450 (CYP) and glutathione S-transferase (GST) enzymes by using homology modeling and molecular docking. The theoretical results obtained were further used to explain the diastereomer- and enantiomer-selective behaviors of HBCD in maize in vivo.

\section{MATERIALS AND METHODS}

Chemicals. Three native HBCD standards $(\alpha-, \beta$-, and $\gamma$ HBCD stereoisomers in toluene, chemical purity $>98 \%)$ were obtained from Accu-Standard (New Haven, CT). The ${ }^{13} \mathrm{C}$ labeled $\alpha$-, $\beta$-, and $\gamma$-HBCDs (purity $\geq 99 \%$ ) were purchased from Cambridge Isotope Laboratories, Inc. (Andover, MA). rac-(1,5R,6S,9S,10R)-Pentabromocyclododecene (PBCD) was provided by Wellington Laboratories, Inc. (Ontario, Canada). All solvents used were of HPLC grade and purchased from J. T. Baker (Deventer, Netherlands). High-purity water was prepared with a Milli-Q system (Millipore, Bedford, MA). Neutral silica gel (100-200 mesh) and alumina (60-100 mesh) were purchased from Fisher Scientific Inc. (Fair Lawn, NJ).

Preparation of Individual HBCD Enantiomers. Enantiomerically pure $\alpha$-, $\beta$-, and $\gamma$-HBCDs were prepared from standards of the racemic $\alpha$-, $\beta$-, and $\gamma$-HBCDs by an Agilent HPLC system (Agilent 1100, Santa Clara, CA) with a diode array detector (DAD). The enantiomeric separation was conducted on a chiral Nucleodex $\beta$-PM column ( $5 \mu \mathrm{m}, 200$ $\mathrm{mm} \times 4 \mathrm{~mm}$ i.d.) from Macherey-Nagel $\mathrm{GmbH} \&$ Co. KG (Düren, Germany) using methanol/water as mobile phase at a flow rate of $0.35 \mathrm{~mL} / \mathrm{min}$. Preparation procedures are described in detail in Supporting Information (SI). Six individual HBCD enantiomers were successfully prepared and the baseline enantiomeric separation achieved for the mixtures of the three pairs of $(+) /(-)-\alpha-, \beta$-, and $\gamma$ - HBCD enantiomers by UPLC-MS/MS is shown in Figure S1 in SI. According to the method described by Heeb et al. ${ }^{4}(-) \alpha-,(-) \beta$-, and $(+) \gamma$ HBCDs were eluted prior to their opposite enantiomers. The purities of the prepared HBCD enantiomers exceed 98\%, and they were found to be stable over half a year when stored at $-20{ }^{\circ} \mathrm{C}$.

Plant Exposure. Plant exposure was carried out according to the methods described in our previous research, ${ }^{34}$ and the details are provided in SI. To minimize metabolism of HBCD caused by anaerobic microorganisms, autoclaved deionized water was used to prepare Hoagland nutrient solution, which was further saturated with oxygen. Exposed solutions were obtained by first dissolving each of the prepared pure $(+) /(-)-\alpha-, \beta-$, and $\gamma$-HBCD enantiomers in methanol individually and then gradually diluting with the sterile $1 / 4$ strength Hoagland nutrient solution. The concentrations of $(+) /(-)-\alpha-, \beta-$, and $\gamma$-HBCD enantiomers in the initial exposure solution were set and determined at 25.0, 17.5, and $2.0 \mathrm{ng} / \mathrm{L}$, respectively, lower than or equal to their water solubility.

Maize (Zea mays L.) seeds were obtained from the Chinese Academy of Agricultural Sciences, Beijing, China. Prior to germination, seeds of similar size were selected and surfacesterilized in $3 \%(\mathrm{v} / \mathrm{v}) \mathrm{H}_{2} \mathrm{O}_{2}$ for $10 \mathrm{~min}$, followed by thoroughly washing with distilled water, and subsequently germinated on moist filter paper for 4 days. After germination, the maize seedlings were transferred to containers containing sterile $1 / 4$ strength Hoagland nutrient solution for cultivation in a controlled environment growth chamber. After 7 days, a batch of five uniformly sized maize seedlings with three leaves for each was transferred to an autoclaved $200 \mathrm{~mL}$ brown glassstoppered flask, which was used as the exposure container. Then $150 \mathrm{~mL}$ of each of the exposure solutions of $(+) /(-)-\alpha$-, 
$\beta$-, and $\gamma$-HBCD enantiomers were added to the exposure container. Unplanted controls with $150 \mathrm{~mL}$ of solution of each individual HBCD enantiomer but without seedlings, and blank controls with seedlings but without $\mathrm{HBCD}$, were set up simultaneously. All treatments were set up in triplicate with separate containers. Maize plants were harvested after $7 \mathrm{~d}$ of exposure. The maize seedlings were freeze-dried at $-50{ }^{\circ} \mathrm{C}$ for $48 \mathrm{~h}$ in a lyophilizer (FD-1, Beijing Boyikang Instrument Ltd., China), separated into roots and shoots, weighed, and finely chopped. The roots and shoots of the five seedlings in each container were combined as one root or shoot sample. Nutrient solutions after plant exposure were filtered with $0.45 \mu \mathrm{m}$ filter membranes. All the samples were stored in glass containers at $-20{ }^{\circ} \mathrm{C}$ before chemical analysis.

HBCD Extraction, Cleanup, and Analysis. A $0.5-1.0 \mathrm{~g}$ (dry weight) amount of plant samples or 5-10 mL of exposed solutions was spiked with $10 \mathrm{ng}$ of surrogates ${ }^{13} \mathrm{C}-\alpha$-HBCD and ${ }^{13} \mathrm{C}-\gamma$-HBCD. The extraction, cleanup, and analysis procedures for HBCDs are based on the method of $\mathrm{Wu}$ et al. ${ }^{15}$ with some modifications. HBCD enantiomers were analyzed by an Acquity UPLC system coupled to a triple-quadrupole mass spectrometer (Waters, Milford, MA). Separation of HBCD enantiomers was carried out on a Nucleodex $\beta$-PM column (5 $\mu \mathrm{m}, 200 \mathrm{~mm} \times 4 \mathrm{~mm}$ i.d.). A mobile phase of A (70:30 methanol:acetonitrile, v:v) and $\mathrm{B}\left(\mathrm{H}_{2} \mathrm{O}\right.$ with $10 \mathrm{mM}$ ammonium acetate) at a flow rate of $0.4 \mathrm{~mL} / \mathrm{min}$ was applied for elution of the target compounds. The MS system was operated in the electrospray (ESI) negative ionization and multiple reaction monitoring (MRM) mode. The conditions for the MS system were optimized as follows: cone voltage, 20 $\mathrm{V}$; capillary voltage, $3.5 \mathrm{kV}$; desolvation temperature, $160{ }^{\circ} \mathrm{C}$; source temperature, $110^{\circ} \mathrm{C}$; nebulizing gas flow, $400 \mathrm{~L} / \mathrm{h}$; cone gas flow, $50 \mathrm{~L} / \mathrm{h}$; collision energy, $15 \mathrm{eV}$. The MRM transitions monitored were $640.6 \rightarrow 79.0$ for $\mathrm{HBCD}$ enantiomers and $652.6 \rightarrow 79.0$ for the ${ }^{13} \mathrm{C}$-labeled HBCDs, respectively. Details of HBCD extraction, cleanup, and analysis are provided in SI.

Quality Assurance and Quality Control. Matrix effects on signal intensity of UPLC-MS/MS were minimized using ${ }^{13} \mathrm{C}-\alpha$ - and ${ }^{13} \mathrm{C}-\gamma$-HBCDs as the surrogate standards and ${ }^{13} \mathrm{C}-\beta$ $\mathrm{HBCD}$ as the internal standard. For every batch of six samples, a solvent blank was added to ensure that the samples were free of contamination. The average recoveries of $\alpha$-, $\beta$-, and $\gamma$ HBCDs were $82.6 \pm 9.50 \%, 90.2 \pm 8.90 \%$, and $86.5 \pm 9.70 \%$ in the spiked matrixes $(n=3)$, respectively. Recoveries of surrogate standard were as follows: $85.7 \pm 9.20 \%$ for ${ }^{13} \mathrm{C}_{12}-\alpha$ $\mathrm{HBCD}, 89.6 \pm 10.3 \%$ for ${ }^{13} \mathrm{C}_{12}-\beta-\mathrm{HBCD}$, and $87.5 \pm 8.40 \%$ for ${ }^{13} \mathrm{C}_{12}-\gamma$-HBCD. The method detection limits (MDLs) for $\alpha$-, $\beta$-, and $\gamma$-HBCDs were $0.78,0.05$, and $0.14 \mathrm{ng} / \mathrm{g}$, respectively. Details of quality assurance and quality control are provided in SI.

Metabolite Identification. An Agilent 6545 Q-TOF LCMS (Santa Clara, CA) was used to identify the possible metabolites of HBCD enantiomers. Q-TOF MS was operated with an electrospray source in negative ion mode. The main instrument setting for the Q-TOF was as follows: drying gas temperature $150{ }^{\circ} \mathrm{C}$, drying gas flow $10 \mathrm{~L} / \mathrm{min}$, capillary voltage $3500 \mathrm{~V}$, fragmentor voltage $100 \mathrm{~V}$. The Q-TOF chromatograms were acquired in a scan range from 50 to $1050 \mathrm{~m} / z$. The $[\mathrm{M}-$ $\mathrm{H}]^{-}$brominated clusters monitored for the putative metabolites of HBCD in maize are listed in Table S1 in SI. It was assumed that the response factors for the isomers of metabolites were equal to each other based on the report by Abdallah et al., ${ }^{35}$ and then the semiquantitative concentrations of the metabolites were determined by using peak area.

Homology Modeling and Molecular Docking. Previous studies have confirmed that CYP450 and GST enzymes play the key roles in the hydroxylation and reduction of xenobiotics such as PCBs and triazine, and CYP71C3v2 and GST31 are the most important CYP450 and GST isozymes in maize, respectively. ${ }^{36,37}$ Therefore, the 3-D structures of CYP71C3v2 and GST31 isozymes were used for homology modeling. The primary sequences of CYP71C3v2 and GST31 are available at the National Center for Biotechnology Information (NCBI) Web site (http://www.ncbi.nlm.nih.gov). The template proteins were identified by the BLAST program (http://blast.ncbi. nlm.nih.gov/Blast.cgi). The human CYP450 1A1 (PDB ID: 4I8V, resolution: $2.60 \AA$ ) and wheat GST TaGST4-4 (PDB ID: 1GWC, resolution: $2.20 \AA$ ) were employed as the templates for CYP71C3v2 and GST31, respectively (Figure S2, SI). The sequence identity was $31 \%$ for CYP71C3v2 to CYP1A1, and $46 \%$ for GST31 to TaGST4-4. CYP71C3v2 contained four $\alpha$ helices and two random coils, and GST31 contained six $\alpha$ helices and four $\beta$ sheets (Figure S3A, SI). The initial 3-D structural models were energy-minimized to release the poor atomic contacts and tune unreasonable local structural conformations. After that, the final models were assessed by the Procheck program to check the stereochemical quality of the protein structure. Concerning the Procheck assessment, the percentage of the residues in the core Ramachandran region were $87.3 \%$ for CYP71C3v2 and $93.5 \%$ for GST31 (Figure $\mathrm{S} 3 \mathrm{~B}, \mathrm{SI})$, respectively. Residues located in the unfavorable regions were far from the substrate-binding domain and did not affect the ligand-protein binding simulations, suggesting that the models of the two plant enzymes are of reasonable quality compared with the crystal structures of the templates.

Molecular interactions of HBCD enantiomers with plant enzymes were characterized by using molecular docking. The structural models of the three pairs of HBCD enantiomers, whose energies were minimized using the molecular mechanics method (MM2), were generated by ChemDraw (CambridgeSoft, Waltham, MA). The docking on the monomer model of plant enzymes with HBCD was performed using Autodock 4.0. Generally, polar hydrogen atoms were added and Kollman charges were assigned to all atoms of the proteins. The docking area was defined using AutoGrid 4. A $40 \times 40 \times 40$ 3-D affinity grid centered around the antifolate binding site was calculated. The spacing between grid points was set as $0.375 \AA$. For the ligand, Gasteiger charges were added, and nonpolar hydrogen atoms were merged. For docking simulations, the Lamarckian genetic algorithm (LGA) was selected for ligand conformation and all bond rotations for ligands were ignored. In the docking protocol the number of individuals in each population was set to 150 and the maximum number of energy evaluations was set to 25000000 , whereas the maximum number of generations was set to 1000 . The maximum number of top individuals, the rate of gene mutation, and crossover were set as default values. Energetic evaluations were calculated using the MOLDOCK score algorithm. The best orientation with the highest docking score was finally selected. The lowest energy docking models were selected from the fine grid docking using several scoring functions for configuration analysis.

Statistical Analysis. Data analysis was performed using SPSS 16.0 (SPSS Inc., Chicago IL). One-way analysis of variance (ANOVA) accompanied by Tukey's test was used to determine the differences in the accumulation and biotransfor- 


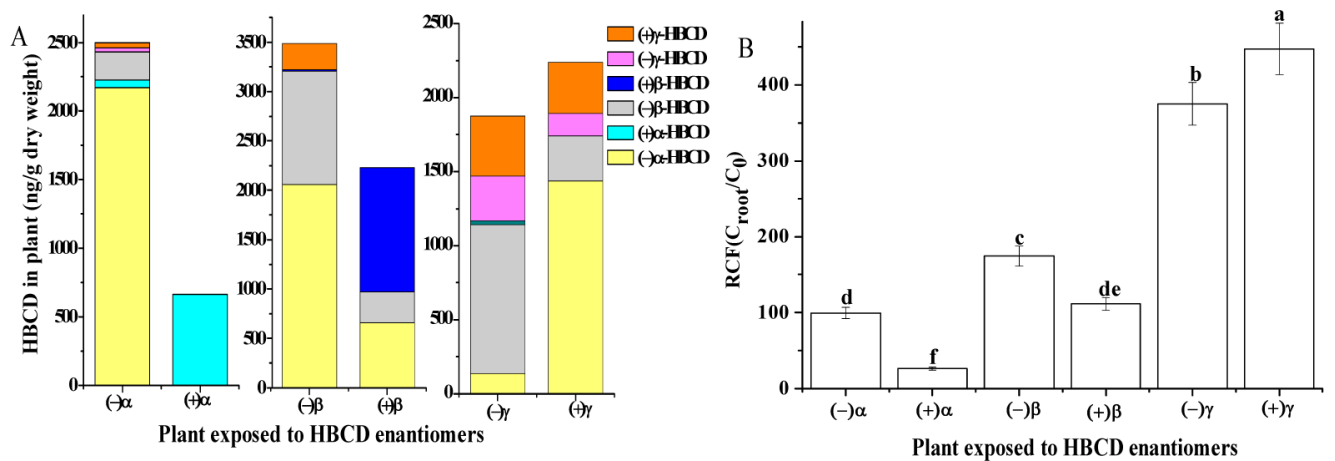

Figure 1. Accumulation (A) and the root concentration factors (RCFs) (B) of $\mathrm{HBCD}$ enantiomers in maize roots exposed to individual $(+) /(-) \alpha-$, $\beta$-, and $\gamma$-HBCD enantiomers, with their concentrations at $25.0,17.5$, and $2.00 \mathrm{ng} / \mathrm{L}$, respectively. Error bars represent standard deviation values. Means $(n=3)$ with the same letter are not significantly different at the $5 \%$ level.
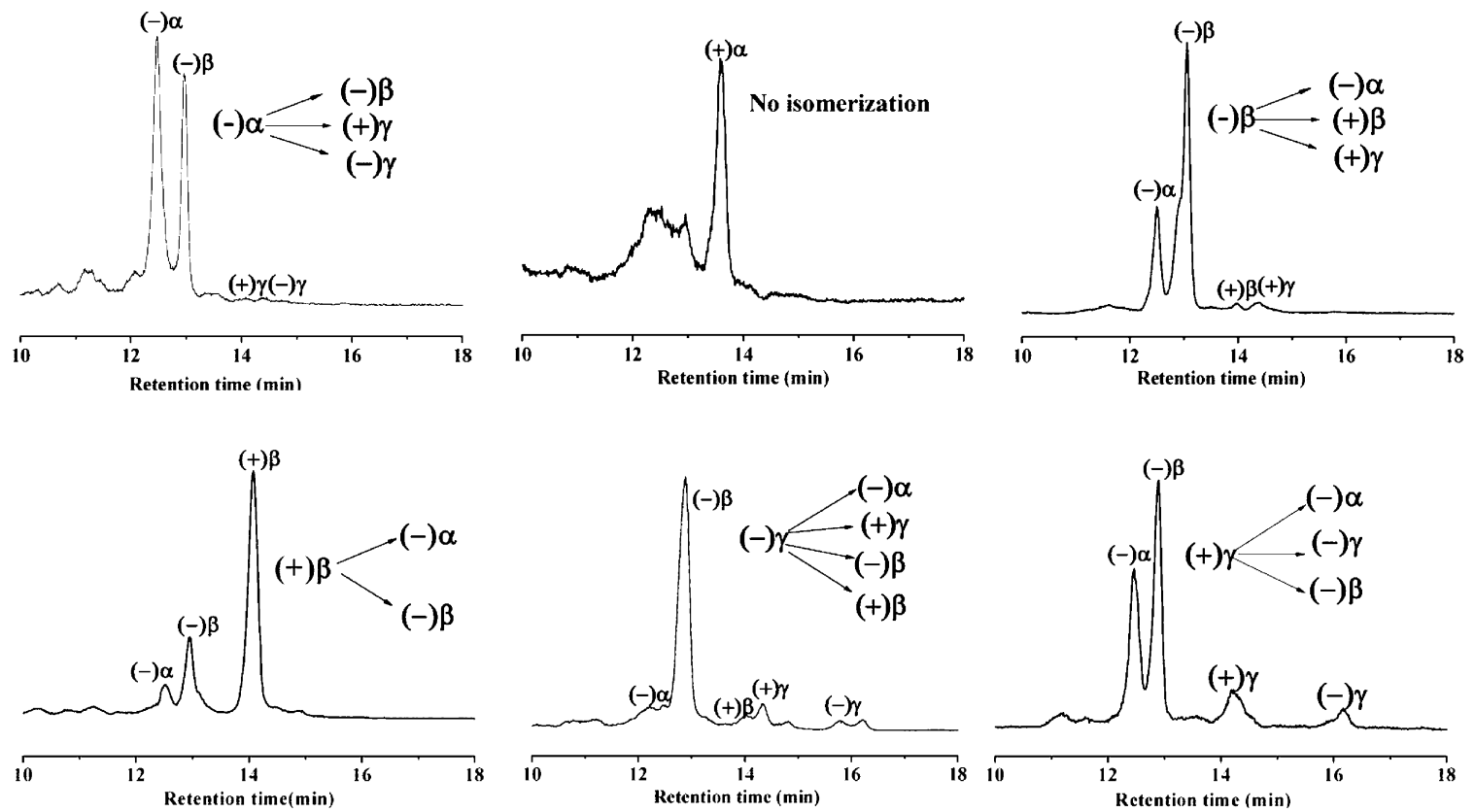

Figure 2. Chromatogram profiles of bioisomerization products when maize was exposed to individual (+)/(-)- $\alpha$-, $\beta$-, and $\gamma$-HBCD enantiomers.

mation of HBCD diastereomers and enantiomers in maize roots. The level of significance was set at $P=0.05$.

\section{RESULTS AND DISCUSSION}

Diastereomer- and Enantiomer-Specific Accumulation of HBCD in Maize. All three pairs of HBCD enantiomers were detected in maize roots (Figure 1A), while none of them was found in the blank controls, indicative of their uptake by roots. HBCD enantiomers were also detected in shoots but at much lower concentrations (Table S2) compared with root concentrations, with root-to-shoot translocation ratios in the range of 0.02-0.06 (Table S3, SI). Therefore, only diastereomer- and enantiomer-specific accumulation of $\mathrm{HBCD}$ in roots will be discussed in the following. Accumulation of $\mathrm{HBCD}$ in maize roots was diastereomerand enantiomer-specific. $(-) \alpha-,(-) \beta-$, and $(+) \gamma$-HBCDs accumulated in maize roots were at the concentrations of 2498,3489 , and $2238 \mathrm{ng} / \mathrm{g}$ based on dry weight, respectively, which were consistently higher than those of their corresponding enantiomers $(665,2230$, and $1876 \mathrm{ng} / \mathrm{g}$ for $(+) \alpha-,(+) \beta$-, and $(-) \gamma$-HBCDs, respectively). Our previous study confirmed the diastereomer-specific uptake and translocation of HBCD by maize, ${ }^{15}$ but no studies have been performed to date regarding its enantiomer-specific uptake by plants. Root concentration factors (RCFs) of the three pairs of HBCD enantiomers were further calculated by dividing the concentration of each enantiomer in maize roots by the equalized concentration in the exposure solution (Figure 1B). The values followed the order $(+) \gamma->(-) \gamma->(-) \beta->(+) \beta->(-) \alpha->(+) \alpha-\mathrm{HBCD}$. RCF values were higher for $(-) \alpha-,(-) \beta$-, and $(+) \gamma$-HBCDs than their corresponding enantiomers, further confirming that $(-) \alpha-, \quad(-) \beta-$, and $(+) \gamma-H B C D$ s were the preferential configurations accumulated in maize. A significant positive correlation was found between the values of log RCF for $\mathrm{HBCD}$ enantiomers and $\log K_{\mathrm{ow}}\left(R^{2}=0.68, P<0.05\right)$ (Figure $S 4$ ), indicating the contribution of hydrophobicity to plant uptake of HBCD enantiomers. Diastereomer- and enantiomerselective accumulation of $\mathrm{HBCD}$ has also been found in organisms. However, the results were inconsistent for different organisms, with some similar to ${ }^{14,38}$ and some different from $^{39,40}$ the results we obtained for maize.

Bioisomerization of HBCD Diastereomers and Enantiomers in Maize. Very limited bioisomerization products (less than $3.1 \%$ of the initial amount) were found in the 

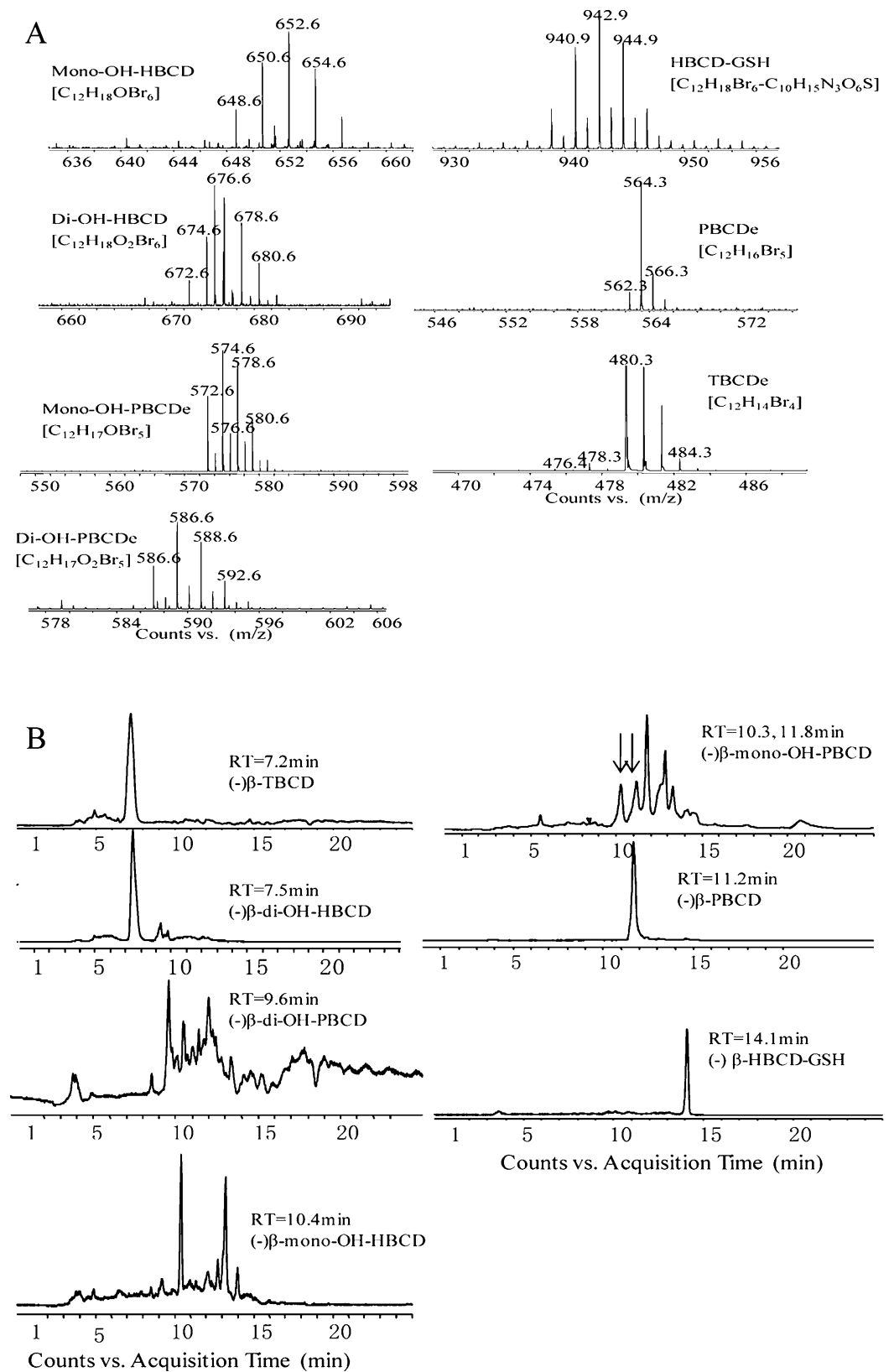

Figure 3. $[\mathrm{M}-\mathrm{H}]^{-}$brominated clusters for the hydroxylated and debrominated metabolites of HBCD enantiomers in maize roots monitored by $\mathrm{Q}-$ TOF LC-MS (A), and the chromatogram profile of metabolites for HBCD enantiomers, taking maize exposed to ( - ) $\beta$-HBCD as an example (B).

solution of the unplanted control (Table S4, SI). The chromatograms of HBCD bioisomerization products in maize roots are shown in Figure 2. Isomerization occurred for all the tested HBCD stereoisomers with the sole exception of $(+) \alpha$ HBCD. Taking $(+) \gamma$-HBCD as an example, it was converted mainly into $(-) \alpha$-HBCD, followed by $(-) \gamma$-HBCD and then $(-) \beta$-HBCD. $(-) \alpha$-HBCD was frequently detected in maize roots after they were exposed to the individual $(+) /(-)-\beta$ - or $\gamma$ HBCD stereoisomers, suggesting the capability of maize roots to bioisomerize $(+) /(-)-\beta$ - or $(+) /(-)-\gamma$-HBCDs to $(-) \alpha$ HBCD. The isomerization rate was further calculated (Table S5, SI), and the results indicated that bioisomerization of $\mathrm{HBCD}$ in maize roots was enantiomer-specific, with the rates for $(-) \alpha-,(-) \beta$-, and $(+) \gamma$-HBCDs higher than those of their corresponding enantiomers. Among the three pairs of $\mathrm{HBCD}$ enantiomers, $(+) /(-)-\gamma$-HBCDs were more prone to isomerization, with isomerization efficiency of $90.5 \pm 8.24 \%$ and 88.5 $\pm 7.98 \%$, respectively. The interconversion pathway of $\mathrm{HBCD}$ is given in Figure S5A in SI by taking the $(+) /(-)-\gamma$-HBCD enantiomers as an example. Conversions of $(-) \gamma$-HBCD to $(-) \alpha$-HBCD and $(+) \gamma$-HBCD to $(+) \alpha-\mathrm{HBCD}$ indicated the occurrence of regio- and stereoselective isomerization of HBCD enantiomers in maize roots. In addition, $(+) /(-)-\beta$ and $\gamma$-HBCDs were stereoselectively rearranged, with $(-) \beta$ $\mathrm{HBCD}$ being converted into $(+) \beta$-HBCD, $(-) \gamma$-HBCD into $(+) \gamma$-HBCD, and vice versa. The diastereomeric shift of $\beta$ - and $\gamma$-HBCDs toward $\alpha$-HBCD in maize was similar to the bioisomerization typically occurring in other organisms such as juvenile rainbow trout and mice, ${ }^{4,42}$ which can be one of the reasons for the dominance of $\alpha$-HBCD in the majority of organisms. $^{43}$ More interestingly, bioisomerization of $(-) \alpha$ HBCD toward $(+) \alpha-,(-) \beta$-, and $(+) /(-)-\gamma$-HBCDs was observed in maize roots, but these isomerization reactions have never been reported for animals. 
GST31
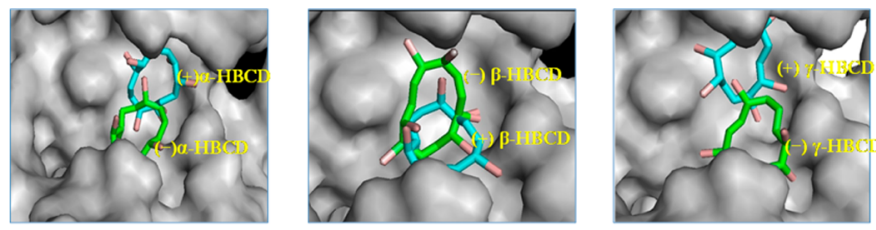

CYP71C3v2
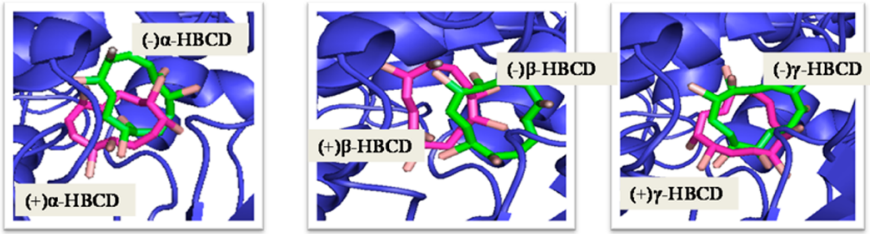

Figure 4. Enantiomer-specific binding modes of HBCDs bound to CYP71C3v2 and GST31. The ligands are represented by stick drawings, and proteins are presented in cartoons.

Table 1. Binding Affinities of HBCD Enantiomers and the Main Interaction Active Site Residues with CYP71C3v2 and GST31

\begin{tabular}{|c|c|c|c|c|c|}
\hline \multirow[b]{2}{*}{ isomer } & \multirow{2}{*}{$\begin{array}{c}\text { length } \\
(\AA)\end{array}$} & \multicolumn{2}{|c|}{$\begin{array}{l}\text { docking energy } \\
(\mathrm{kcal} / \mathrm{mol})\end{array}$} & \multicolumn{2}{|c|}{ active site residues } \\
\hline & & CYP71C3v2 & GST31 & CYP71C3v2 & GST31 \\
\hline$(-) \alpha-\mathrm{HBCD}$ & 8.3 & -6.72 & -7.57 & $\begin{array}{c}\text { Trp151, Pro476, Cys475, Ile474, Arg473, Ala143, } \\
\text { Phe468 }\end{array}$ & Leu11, Ser14, Phe16, Trp110, Ala114, L115, Phe222 \\
\hline$(+) \alpha-\mathrm{HBCD}$ & 8.3 & -7.82 & -7.39 & $\begin{array}{c}\text { Arg126, Leu401, Leu400, Leu519, Asn326, Ala330, } \\
\text { His403 }\end{array}$ & $\begin{array}{c}\text { Leu11, Pro13, Ser14, Lys54, Ile55, Trp168, Phe212, } \\
\text { Phe222 }\end{array}$ \\
\hline$(-) \beta-\mathrm{HBCD}$ & 8.5 & -7.60 & -7.29 & $\begin{array}{c}\text { Arg136, Arg155, Ala330, Thr334, Phe468, Cys475, } \\
\text { Met520 }\end{array}$ & $\begin{array}{l}\text { Leu11, Pro13, Ser14, Val38, Lys54, Ile55, Trp110, } \\
\text { Trp168, Phe222 }\end{array}$ \\
\hline$(+) \beta-\mathrm{HBCD}$ & 7.6 & -7.35 & -7.15 & $\begin{array}{c}\text { Arg128, Asla330, Luer 399, Lys475, Leu399, Leu519, } \\
\text { Met520 }\end{array}$ & $\begin{array}{c}\text { Leu11, Pro13, Ser14, Val38, Trp110, Ala111, Trp168, } \\
\text { Phe222 }\end{array}$ \\
\hline$(-) \gamma-\mathrm{HBCD}$ & 8.3 & -7.92 & -7.75 & $\begin{array}{l}\text { Arg126, Ala143, Ala330, Thr334, Phe468, Cys475, } \\
\text { Leu519 }\end{array}$ & $\begin{array}{l}\text { Pro13, Ser14, Trp110, Ala111, Trp168, Phe222, } \\
\text { Ser223, Asn227 }\end{array}$ \\
\hline$(+) \gamma-\mathrm{HBCD}$ & 9.3 & -7.34 & -8.42 & $\begin{array}{c}\text { Pro467, Thr334, Gly397, Ala330, Leu400, Leu401, } \\
\text { Asn326 }\end{array}$ & $\begin{array}{l}\text { Leu11, Phe16, Val38, Lys41, Lys53, Ile55, Trp168, } \\
\text { Phe222 }\end{array}$ \\
\hline
\end{tabular}

Metabolization of HBCD in Maize by Debromination and Hydroxylation. The metabolites derived from each $\mathrm{HBCD}$ enantiomer in maize roots were identified (Figure 3), but none of them was detected in shoots. To exclude the possibility for maize roots to take up metabolites directly from nutrition solutions, the solutions of unplanted controls were analyzed and no metabolite product was detected. The mass balance of HBCD and metabolites was further calculated, and the results (Table S4) showed that the products of isomerization, debromination, and hydroxylation in solution after plant exposure were $0.08-0.5,0.009-0.07$, and $0.002-0.02 \mathrm{ng} /$ $\mathrm{mL}$ (Table S2), accounting for $0.04-3.84 \%, 0.05-0.27 \%$, and $0.03-0.09 \%$ of their total mass (Table S4), respectively. This suggests that the contribution of microbial biotransformation of HBCD in solution to root accumulation of metabolites can be neglected.

The metabolites detected in roots included monoglutathione (GSH)-HBCD adducts, hydroxylated mono- and di-OHHBCDs and mono- and di-OH-pentabromocyclododecanols (OH-PBCDs), and debrominated pentabromocyclododecenes (PBCDEs) and tetrabromocyclododecenes (TBCDEs) (Figure $3 A)$. Higher polarity di- and monohydroxyl metabolites eluted earlier than the debrominated metabolites, while the latter eluted earlier than their respective HBCD isomers (Figure 3B), consistent with the observations obtained for three wildlife species (tern egg, seal, and flounder) and Wistar rats. ${ }^{24}$ The results suggested that debromination and hydroxylation were the two metabolic pathways for HBCDs in maize (Figure S5B,C in SI). Debrominated and hydroxylated metabolites have also been detected in both abiotic and biotic samples; , $23,24-46^{2}$ however, there has been no research involving the selective debromination and hydroxylation biotransformation in organisms at the individual HBCD enantiomer level. Patterns of debrominated and hydroxylated derivatives from each HBCD enantiomer in maize roots were distinct (Table S1 in SI). For example, two mono- and two di-OH-PBCDs and two OHHBCDs were obtained from $(-) \beta$-HBCD, while no mono-OH$\mathrm{HBCD}$ or di-OH-PBCD were formed from $\beta(+)-\mathrm{HBCD}$, and HBCD-GSH conjugates only appeared for the transformation of $(+) /(-)-\beta-,(-) \alpha$-, and $(+) \gamma$-HBCDs. Unfortunately, native or isotopically labeled commercial standards for these isolated metabolites are unavailable, precluding accurate quantification of their concentrations. Therefore, a semiquantitative analysis was performed using peak areas. It was interestingly found that more debrominated products were detected in maize roots after being exposed to $(-) \alpha-,(-) \beta$-, and $(+) \gamma$-HBCDs, while more hydroxylated products were obtained for the exposures to $(+) \alpha-, \quad(-) \beta-$, and $(-) \gamma-\mathrm{HBCD}$ s compared with their corresponding enantiomers (Figure S6), which further confirmed that metabolization of $\mathrm{HBCD}$ by debromination and hydroxylation in maize was enantiomer-specific and selective.

Molecular Interactions between HBCD and Plant Enzymes. The above results provided experimental evidence of diastereomer- and enantiomer-selective accumulation and biotransformation of the individual HBCD enantiomers in maize roots. It is necessary to gain further insight into the molecular mechanisms involved in the selective interactions 
between $\mathrm{HBCD}$ enantiomers and maize roots. Selective molecular interactions of HBCD enantiomers with maize enzymes CYP71C3v2 and GST31 were characterized by homology modeling and molecular docking methods. All three pairs of $\mathrm{HBCD}$ enantiomers could be docked into the active cavities of maize enzymes CYP71C3v2 and GST31 (Figure S7 in SI), and the locations and conformations were diastereo- and enantio-distinct (Figure 4 and Figure S8 in SI). When HBCD enantiomers were docked into CYP71C3v2 and GST31, eight residues including Pro476, Arg126, Leu401, Leu400, Asn326, Phe468, Cys475, and Thr334 in the active site of CYP71C3v2, and six main residues including Leu11, Ser14, Pro13, Trp110, Trp168, and Phe222 in the active site of GST31, were found to be located within a distance of $5 \AA$ to the HBCD enantiomer and suggested their important roles in binding to the HBCD enantiomers (Table 1 and Figure S9 in $\mathrm{SI})$. All these amino acid residues were hydrophobic and would bind with hydrophobic compounds such as HBCD mainly via hydrophobic effects. ${ }^{47}$ Furthermore, HBCD enantiomers also showed distinctly different binding modes with the residues in the active sites of maize enzymes. Taking the interaction of $(+) /(-)-\alpha$-HBCDs with maize enzymes as an example, $(-) \alpha$ HBCD formed one halogen bond with the residues of Arg473 and Cys476 of CYP71C3v2, respectively, whereas (+) $\alpha$-HBCD formed one halogen bond with the residue of Asn326 (Figure S9a in SI). (+) $\alpha$-HBCD did not form halogen bonds with GST31 residues, while $(-) \alpha$-HBCD formed halogen bonds with the residue Ser14 of GST31 (Figure S9b in SI). The binding affinity values of $\mathrm{HBCD}$ enantiomers were within the range of -7.92 to $-6.72 \mathrm{kcal} / \mathrm{mol}$ for CYP71C3v2 and -8.42 to $-7.15 \mathrm{kcal} / \mathrm{mol}$ for GST31 (Table 1), respectively. Compared with the van der Waals force, the binding energy through electrostatic interaction was negligible (Table S6), suggesting that HBCD enantiomers were bound to the active sites of CYP71C3v2 and GST31 mainly via van der Waals forces. The binding affinity of HBCD with plant enzymes exhibited both enantiomer-specific differences and enzyme selectivity. (-) $\alpha-, \quad(-) \beta$-, and $(+) \gamma$-HBCDs, with binding affinities higher than those of their corresponding enantiomers, were found to fit better into the active sites of GST31 (Table $1)$, which was consistent with the experimental results that more $(-) \alpha-,(-) \beta$-, and $(+) \gamma$-HBCDs were isomerized and debrominated in maize. It has been reported that GST enzymes exhibit catalytic activities in the reduction and isomerization reactions of xenobiotics in plants, ${ }^{48}$ whereas $(+) \alpha$-, $(-) \beta$-, and $(-) \gamma$-HBCDs were the preferential binding conformations for CYP71C3v2, suggesting that these three isomers were more easily metabolized by CYP71C3v2. This is in accordance with the experimental results obtained, where hydroxylation reactions were easier for these three conformations than for their corresponding enantiomers (Figure S6). Therefore, enantioselective biotransformation of HBCD enantiomers may derive from their different binding affinities and binding modes to maize enzymes.

Environmental Implications. This study demonstrated that accumulation of HBCDs in maize roots was diastereomerand enantiomer-specific. Patterns of isomerization, debromination, and hydroxylation metabolites for each HBCD enantiomer were significantly different, which comprehensively confirmed the enantioselective biotransformation of HBCDs in maize roots. Molecular interaction between the individual HBCD enantiomers and maize enzymes of CYP71C3v2 and GST31 well explained the diastereomer- and enantiomer- selective in vivo biotransformation of $\mathrm{HBCD}$ in maize roots. This study provided both experimental and theoretical evidence for steroisomer-specific biotic processes of HBCD in maize. To clarify diastereomer- and enantiomer-selective metabolic pathways of HBCDs in maize, this study was conducted under hydroponic conditions. However, due to its hydrophobic character, HBCD is strongly bound to soil particles particularly to soil organic matter, which substantially decreases the uptake by plants. Therefore, there is a gap between the results obtained for $\mathrm{HBCD}$ in this study and its behavior in the real environment, and further investigation of the diastereomerand enantiomer-selective behavior of HBCD in the soil-plant system is necessary.

\section{ASSOCIATED CONTENT}

\section{Supporting Information}

The Supporting Information is available free of charge on the ACS Publications website at DOI: 10.1021/acs.est.6b03223.

Detailed extraction and analytical methods of HBCD and chiral separation of HBCD enantiomers by using UPLCMS/MS, detection frequency of debrominated and hydroxylated products in maize, mass balance of HBCD, 3-D structures of CYP71C3v2 and GST31, and HBCD diastereomer- and enantiomer-specific binding with plant enzymes, including nine figures and six tables (PDF)

\section{AUTHOR INFORMATION}

\section{Corresponding Author}

*Phone: +86 10 62849683. Fax: +86 10 62923563. E-mail: szzhang@rcees.ac.cn.

\section{Notes}

The authors declare no competing financial interest.

\section{ACKNOWLEDGMENTS}

This work was supported by the National Natural Science Foundation of China (projects 21537005, 21577155, and 21321004), and the Strategic Priority Research Program of the Chinese Academy of Sciences (XDB14020202).

\section{REFERENCES}

(1) Covaci, A.; Gerecke, A. C.; Law, R. J.; Voorspoels, S.; Kohler, M.; Heeb, N. V.; Leslie, H.; Allchin, C. R.; de Boer, J. Hexabromocyclododecanes (HBCDs) in the environment and humans: A review. Environ. Sci. Technol. 2006, 40 (12), 3679-3688.

(2) UNEP. United Nations Environment Programme. Report of the conference of the parties of the Stockholm convention on persistent organic pollutants on the work of its sixth meeting. UNEP/POPS/ COP6. June 2013.

(3) Koch, C.; Schmidt-Kotters, T.; Rupp, R.; Sures, B. Review of hexabromocyclododecane (HBCD) with a focus on legislation and recent publications concerning toxicokinetics and -dynamics. Environ. Pollut. 2015, 199, 26-34.

(4) Heeb, N. V.; Schweizer, W. B.; Kohler, M.; Gerecke, A. C. Structure elucidation of hexabromocyclododecanes - A class of compounds with a complex stereochemistry. Chemosphere 2005, 61 (1), 65-73.

(5) Liu, W. P.; Gan, J. Y.; Schlenk, D.; Jury, W. A. Enantioselectivity in environmental safety of current chiral insecticides. Proc. Natl. Acad. Sci. U. S. A. 2005, 102 (3), 701-706.

(6) Remberger, M.; Sternbeck, J.; Palm, A.; Kaj, L.; Strömberg, K.; Brorström-Lundén, $\mathrm{E}$. The environmental occurrence of hexabromocyclododecane in Sweden. Chemosphere 2004, 54 (1), 9-21. 
(7) Petersen, M.; Hamm, S.; Esser, U. Comparative GC/MS and LC/MS detection of hexabromocyclododecane (HBCD) in soil and water samples. Organohalogen Compd. 2004, 66, 226-231.

(8) Desborough, J. L. Exploring the utility of chiral signatures to further understanding of soil-to-herbage tansfer of persistent organic pollutants (POPs); University of Birmingham: United Kingdom, 2011.

(9) Gao, H. T.; Wang, J. Z.; Yu, Z. Q.; Guo, Q. R.; Sheng, G. Y.; Fu, J. M. Hexabromocyclododecanes in surface soils from e-waste recycling areas and industrial areas in south China: Concentrations, diastereoisomer- and enantiomer-specific profiles, and inventory. Environ. Sci. Technol. 2011, 45 (6), 2093-2099.

(10) Jin, J.; Yang, C. Q.; Wang, Y.; Liu, A. M. Determination of hexabromocyclododecane diastereomers in soil by ultra performance liquid chromatography-electrospray ion source/tandem mass spectrometry. Chin. J. Anal. Chem. 2009, 37 (4), 585-588.

(11) Tang, J. F.; Feng, J. Y.; Lia, X. H.; Li, G. Levels of flame retardants HBCD, TBBPA and TBC in surface soils from an industrialized region of East China. Environ. Sci. Processes Impacts 2014, 16 (5), 1015-1021.

(12) Janák, K.; Covaci, A.; Voorspoels, S.; Becher, G. Hexabromocyclododecane in marine species from the western Scheldt Estuary: Diastereoisomer- and enantiomer-specific accumulation. Environ. Sci. Technol. 2005, 39 (7), 1987-1994.

(13) Haukas, M.; Hylland, K.; Nygard, T.; Berge, J. A.; Mariussen, E. Diastereomer-specific bioaccumulation of hexabromocyclododecane (HBCD) in a coastal food web, Western Norway. Sci. Total Environ. 2010, 408 (23), 5910-5916.

(14) Tomy, G. T.; Pleskach, K.; Oswald, T.; Halldorson, T.; Helm, P. A.; Macinnis, G.; Marvin, C. H. Enantioselective bioaccumulation of hexabromocyclododecane and congener-specific accumulation of brominated diphenyl ethers in an eastern Canadian arctic marine food web. Environ. Sci. Technol. 2008, 42 (10), 3634-3639.

(15) Wu, T.; Wang, S.; Huang, H. L.; Zhang, S. Z. Diastereomerspecific uptake, translocation, and toxicity of hexabromocyclododecane diastereoisomers to maize. J. Agric. Food Chem. 2012, 60 (34), 85288534.

(16) Wu, T.; Huang, H. L.; Zhang, S. Z. Accumulation and phytotoxicity of technical hexabromocyclododecane in maize. $J$. Environ. Sci. 2016, 42, 97-104.

(17) Li, Y. N.; Zhou, Q. X.; Wang, Y. Y.; Xie, X. J. Fate of tetrabromobisphenol $\mathrm{A}$ and hexabromocyclododecane brominated flame retardants in soil and uptake by plants. Chemosphere 2011, 82 (2), 204-209.

(18) Zhang, Y. W.; Sun, H. W.; Liu, F.; Dai, Y. Y.; Qin, X. B.; Ruan, Y. F.; Zhao, L. J.; Gan, Z. W. Hexabromocyclododecanes in limnic and marine organisms and terrestrial plants from Tianjin, China: Diastereomer and enantiomer-specific profiles, biomagnification, and human exposure. Chemosphere 2013, 93 (8), 1561-1568.

(19) Zhu, H. K.; Sun, H. W.; Zhang, Y. W.; Xu, J. Y.; Li, B.; Zhou, Q. $\mathrm{X}$. Uptake pathway, translocation, and isomerization of hexabromocyclododecane diastereoisomers by wheat in closed chambers. Environ. Sci. Technol. 2016, 50 (5), 2652-2659.

(20) Zegers, B. N.; Mets, A.; van Bommel, R.; Minkenberg, C.; Hamers, T.; Kamstra, J. H.; Pierce, G. J.; Boon, J. P. Levels of hexabromocyclododecane in harbor porpoises and common dolphins from western European seas, with evidence for stereoisomer-specific biotransformation by cytochrome P450. Environ. Sci. Technol. 2005, 39 (7), 2095-2100.

(21) Abdallah, M. A.; Harrad, S. Tetrabromobisphenol-A, hexabromocyclododecane and its degradation products in UK human milk: relationship to external exposure. Environ. Int. 2011, 37 (2), 443-448.

(22) Abdallah, M. A.; Ibarra, C.; Neels, H.; Harrad, S.; Covaci, A. Comparative evaluation of liquid chromatography-mass spectrometry versus gas chromatography-mass spectrometry for the determination of hexabromocyclododecanes and their degradation products in indoor dust. J. Chromatogr. A 2008, 1190 (1-2), 333-341.

(23) Hiebl, J.; Vetter, W. Detection of hexabromocyclododecane and its metabolite pentabromocyclododecene in chicken egg and fish from the official food control. J. Agric. Food Chem. 2007, 55 (9), 33193324.

(24) Esslinger, S.; Becker, R.; Maul, R.; Nehls, I. Hexabromocyclododecane enantiomers: Microsomal degradation and patterns of hydroxylated metabolites. Environ. Sci. Technol. 2011, 45 (9), 39383944.

(25) Sandermann, H. Higher-plant metabolism of xenobiotics - The green liver concept. Pharmacogenetics 1994, 4, 225-241.

(26) Smith, S. W. Chiral toxicology: It's the same thing $\cdots$ only different. Toxicol. Sci. 2009, 110 (1), 4-30.

(27) Kania-Korwel, I.; Hrycay, E. G.; Bandiera, S. M.; Lehmler, H. J. $2,2^{\prime}, 3,3^{\prime}, 6,6^{\prime}$-Hexachlorobiphenyl (PCB 136) atropisomers interact enantioselectively with hepatic microsomal cytochrome P450 enzymes. Chem. Res. Toxicol. 2008, 21 (6), 1295-1303.

(28) Hoekstra, P. F.; Burnison, B. K.; Neheli, T.; Muir, D. C. Enantiomer-specific activity of o, $\mathrm{p}^{\prime}$-DDT with the human estrogen receptor. Toxicol. Lett. 2001, 125 (1-3), 75-81.

(29) Hayes, J. D.; Flanagan, J. U.; Jowsey, I. R. Glutathione transferases. Annu. Rev. Pharmacol. Toxicol. 2005, 45, 51-88.

(30) Rupasinghe, S.; Schuler, M. A. Homology modeling of plant cytochrome P450s. Phytochem. Rev. 2006, 5 (2), 473-505.

(31) Zhang, W.; Modén, O.; Tars, K.; Mannervik, B. Structure-based redesign of GST A2-2 for enhanced catalytic efficiency with azathioprine. Chem. Biol. 2012, 19 (3), 414-421.

(32) Syed, K.; Porollo, A.; Lam, Y. W.; Grimmett, P. E.; Yadav, J. S. CYP63A2, a catalytically versatile fungal P450 monooxygenase capable of oxidizing higher-molecular-weight polycyclic aromatic hydrocarbons, alkylphenols, and alkanes. Appl. Environ. Microbiol. 2013, 79 (8), 2692-2702.

(33) Yoo, J.; Hirano, M.; Mizukawa, H.; Nomiyama, K.; Agusa, T.; Kim, E. Y.; Tanabe, S.; Iwata, H. In vitro and in silico analyses for predicting hepatic cytochrome P450-dependent metabolic potencies of polychlorinated biphenyls in the Baikal Seal. Environ. Sci. Technol. 2015, 49 (24), 14588-14596.

(34) Xu, X. H.; Wen, B.; Huang, H. L.; Wang, S.; Han, R. X.; Zhang, S. Z. Uptake, translocation and biotransformation kinetics of BDE-47, 6-OH-BDE-47 and 6-MeO-BDE-47 in maize (Zea mays L.). Environ. Pollut. 2016, 208, 714-722.

(35) Abdallah, M. A. E.; Uchea, C.; Chipman, J. K.; Harrad, S. Enantioselective biotransformation of hexabromocyclododecane by in vitro rat and trout hepatic sub-cellular fractions. Environ. Sci. Technol. 2014, 48 (5), 2732-2740.

(36) Persans, M. W.; Wang, J.; Schuler, M. A. Characterization of maize cytochrome P450 monooxygenases induced in response to safeners and bacterial pathogens. Plant Physiol. 2001, 125 (2), 11261138.

(37) Milligan, A. S.; Daly, A.; Parry, M. A. J.; Lazzeri, P. A.; Jepson, I. The expression of a maize glutathione $S$-transferase gene in transgenic wheat confers herbicide tolerance, both in planta and in vitro. Mol. Breed. 2001, 7 (4), 301-315.

(38) Vorkamp, K.; Bester, K.; Riget, F. F. Species-specific time trends and enantiomer fractions of hexabromocyclododecane (HBCD) in biota from East Greenland. Environ. Sci. Technol. 2012, 46 (19), 10549-10555.

(39) Hakk, H.; Szabo, D. T.; Huwe, J.; Diliberto, J.; Birnbaum, L. S. Novel and distinct metabolites identified following a single oral dose of $\alpha$ - or $\gamma$ - hexabromocyclododecane in mice. Environ. Sci. Technol. 2012, 46 (24), 13494-13503.

(40) Zhang, Y. W.; Sun, H. W.; Ruan, Y. F. Enantiomer-specific accumulation, depuration, metabolization and isomerization of hexabromocyclododecane (HBCD) diastereomers in mirror carp from water. J. Hazard. Mater. 2014, 264, 8-15.

(41) Law, K.; Palace, V. P.; Halldorson, T.; Danell, R.; Wautier, K.; Evans, B.; Alaee, M.; Marvin, C.; Tomy, G. T. Dietary accumulation of hexabromocyclododecane diastereoisomers in juvenile rainbow trout (Oncorhynchus mykiss) I: Bioaccumulation parameters and evidence of bioisomerization. Environ. Toxicol. Chem. 2006, 25 (7), 1757-1761.

(42) Szabo, D. T.; Diliberto, J. J.; Hakk, H.; Huwe, J. K.; Birnbaum, L. S. Toxicokinetics of the flame retardant hexabromocyclododecane 
gamma: Effect of dose, timing, route, repeated exposure, and metabolism. Toxicol. Sci. 2010, 117 (2), 282-293.

(43) Li, B.; Yao, T. Q.; Sun, H. W.; Zhang, Y. W.; Yang, J. R. Diastereomer- and enantiomer-specific accumulation, depuration, bioisomerization, and metabolism of hexabromocyclododecanes (HBCDs) in two ecologically different species of earthworms. Sci. Total Environ. 2016, 542, 427-434.

(44) Brandsma, S. H.; Van der Ven, L. T.; De Boer, J.; Leonards, P. E. Identification of hydroxylated metabolites of hexabromocyclododecane in wildlife and 28-days exposed Wistar rats. Environ. Sci. Technol. 2009, 43 (15), 6058-6063.

(45) Heeb, N. V.; Wyss, S. A.; Geueke, B.; Fleischmann, T.; Kohler, H. -P. E.; Schweizer, W. B.; Moor, H.; Lienemann, P. Stereochemistry of enzymatic transformations of $(+) \beta$ - and $(-) \beta$-HBCD with LinA2 A HCH-degrading bacterial enzyme of Sphingobium indicum B90A. Chemosphere 2015, 122, 70-78.

(46) Heeb, N. V.; Zindel, D.; Geueke, B.; Kohler, H. -P. E.; Lienemann, P. Biotransformation of hexabromocyclododecanes (HBCDs) with $\mathrm{LinB}$ - An $\mathrm{HCH}$-converting bacterial enzyme. Environ. Sci. Technol. 2012, 46 (12), 6566-6574.

(47) Lu, Z.; Wong, C. S. Factors affecting phase I stereoselective biotransformation of chiral polychlorinated biphenyls by rat cytochrome P-450 2B1 isozyme. Environ. Sci. Technol. 2011, 45 (19), 8298-3305.

(48) Chronopoulou, E.; Axarli, I.; Nianiou-Obeidat, I.; Madesis, P.; Tsaftaris, A.; Labrou, N. E. Structure and antioxidant catalytic function of plant glutathione transferases. Curr. Chem. Biol. 2011, 5 (1), 1-11. 